\title{
The HDR Process: Reflection on the Motivational Factors, Academic Model, Influences and Challenges That Enabled an Academic to Complete Her Thesis Part-Time
}

\author{
Marie B. Fisher \\ The Australian Catholic University \\ Australia
}

\begin{abstract}
What were the motivational factors and influences throughout the higher degree study process that enabled a full time academic to overcome professional and personal obstacles and complete their research degree? The aim of this paper is to reflect upon the first of a three-stage process of Higher degree research transformational learning and teaching that emerged during the learning journey of an academic who was also a student. This paper provides a reflective overview, supported, informed, and guided by literature and educational theories, of how the process emerged and was adjusted to turn challenges into successes. It will address the impact of first impressions from the author about the HDR journey, perception of supervisors' views, external influences and advice that were used to jump over hurdles, scaffold learning and achieve milestones which ultimately led to completion of a research degree while the student was working full time. This reflective practice research is a work in progress.
\end{abstract}

\section{Introduction}

The purpose of this article is to provide a snapshot of a first impression, reflective introduction to events that influenced my decision to embark on a journey as an HDR student, my perceptions of the HDR process and some key issues that impacted upon my success and how I managed the situation.

This paper articulates a reflective narrative approach, using Gibbs' 1988 model of reflection, French and Raven's 1959 Power types, and educational theories to inform and guide my analysis. In this study I will identify and explain issues that impacted upon my ability to progress the thesis and perception of feedback from the HDR supervision team. In this narrative, the background and context will show how previous part-time study success influenced my approach to undertaking a substantial thesis, giving me an unrealistic sense of what was expected by the HDR supervision team and the
University of New England, Australia. In addition, my motivation for embarking on a thesis journey namely for personal achievement and to obtain secure employment as an academic will be explored.

In the Impressions section of the thesis, I include the reflective story which explains how I became interested in the topic. Integrated into this reflection are experiential and transformative learning theories that informed, guided, and supported my comprehension, when looking back, of my Disorientating Dilemma (the thesis), thinking, writing, and sequencing an argument supported by a body of evidence.

At the end of this section a scholarly analysis of The Thesis Model will be conducted to determine the impact that the apprentice (student) vs expert (HDR supervisor) had on me. Furthermore, a dialogue about how this model departs from contemporary approaches to student-centred learning will be explored. Knowledge and knowing how the micro (interpersonal relations) and the macro (structures, rules, and regulations) should and are applied will be analysed using Knowles' theory of adult learning. His framework will be used to show how the self-concept of a student from dependent on the supervisor to a self-directed learner will be reviewed. Knowles' approach will help to demonstrate how barriers impact on mature aged students' ability to regularly engage in research and know how (and what) to ask for assistance from the HDR supervision team.

Issues that impacted upon my ability to stay engaged in the thesis process will be discussed in the context of perceived and actual power types that emerged during this thesis journey. Then an examination of different types of motivation, supported by personal networks will be discussed to show how thesis completion was achieved.

\section{Background}

Completing a thesis was always a key goal in my academic studies. Despite reading all the books, 
journal articles and blogs about completing an MPhil and $\mathrm{PhD}$ thesis I was unsure whether I would be able to produce a thesis. I misunderstood the requirements. The Higher Degree by Research (HDR) journey was a mystery. There are many rules and regulations that guide and support the process and completion of one's research thesis that are helpful to the candidate and important to know. However, when one reflects on the experience prior to commencing a thesis it is evident that diverse candidates require different levels and types of support, encouragement, intrinsic motivation, and endurance. An important question to ask yourself is 'Why do I want to study and complete a thesis?' to determine motivation to navigate the twisted, perilous journey. Finishing a thesis is rite of passage to working in academia for many aspiring academics. What makes my situation different is that I had to navigate and overcome hurdles that I could not have predicted to occur in rapid succession to enable me to alter my perceptions and expectations and complete the thesis.

\section{Context}

While contemplating studying for my higher degree I managed to secure a long-term contract with my University which led to a tenured permanent position. This type of opportunity does not always eventuate when working on contract, so I knew that this was a chance to build and establish an academic career. I had worked as an academic previously at the Australian National University and the University of Canberra but was limited to academic teaching responsibilities. Therefore, I had experience working as an academic as well as studying part-time.

Previously I managed that effectively, so I thought I would be successful. I was encouraged by my Head of School to enrol in a Higher Degree by research. She explained that I needed to gain my $\mathrm{PhD}$ to obtain ongoing employment in a competitive sector of the workforce. However, I soon realised that Academic workloads are substantial, involving teaching, cultivating collaborations, research, meetings as well as substantial academic administration leaving little time for study, let alone production of publications, and maintaining regular contact with your HDR supervisors [1].

\section{Impressions of the HDR Journey}

The thesis in question entitled 'Imperial Women and Power in Sixth Century Byzantium' was a long and arduous journey that took approximately 9 years to complete. There were many stops and starts along the way due mostly to unexpected challenges including issues arising during the Covid 19 pandemic at the very end of the process. Upon reflection I realise now that $\mathrm{I}$ had the motivation and academic ability to complete the degree, but I misjudged the process of studying for a higher degree by research.

At the beginning of my candidature my understanding of the process was that the thesis journey was very straightforward, linear and milestones could be easily time bound. I believed it would be easier to continue studying after my MA had been completed to keep practicing good study habits. I was mistaken. It became obvious in the first few months that I needed a break from study. As my candidature progressed it was clear that he processes could be divided up into categories such as: student vs supervisor relationships, undertaking reading, review of literature, developing clear research questions, writing your sections for chapters, and finally completing your thesis plus editing. Then you would submit for examination, presumably once the HDR supervisors had signed it off. It would take considerable work, but it was achievable.

Expectations and understandings of the HDR supervision was that a person was assigned or chose a supervisor or supervision team. This HDR supervision team would read all your drafts and provide comprehensive feedback via email within a few days or a week; supervisors were always right as they had the vast experience and had obtained their $\mathrm{PhD}$ and academic standing and this process would be predictable so that one could see progress. It was not linear and the type of feedback I thought I needed I did not get. In addition, I learned that there are disadvantages as well as advantages to picking a world-renowned supervisor, as they were often too busy to meet regularly with students. My expectations were unrealistic.

I am interested in Byzantine and Medieval history in addition to Higher Education Teaching and Information technology. I performed well in my Master of Arts (Byzantine History coursework) and was highly motivated to progress to a thesis. As I had not completed an honours year in any previous studies, I was encouraged to enrol in the MA Hons and, once I had completed a few chapters this would be upgraded to a $\mathrm{PhD}$. It did not happen for various reasons. My original supervisor is an authority on Byzantine Empresses and Power, and she encouraged me to develop a topic. I was satisfied with the topic and found that interest and a desire to answer the power questions helped spur me on.

\section{Reflection Framework}

As I progressed through the long process of researching and producing a thesis I engaged in considerable reflection. At the time I felt that perhaps I had wasted valuable reading time. In hindsight I realise that reflecting on my challenges, achievements, relationships with HDR supervisors and support from my family and friends were extremely helpful. Gibbs 1988 model of reflection 
was an important framework used to support key learning that I am communicating to students and scholars in this article [2]. It was important to integrate a scholarly dimension into my recollection of the thesis experience.

Table 1: Reflective SWOT Analysis

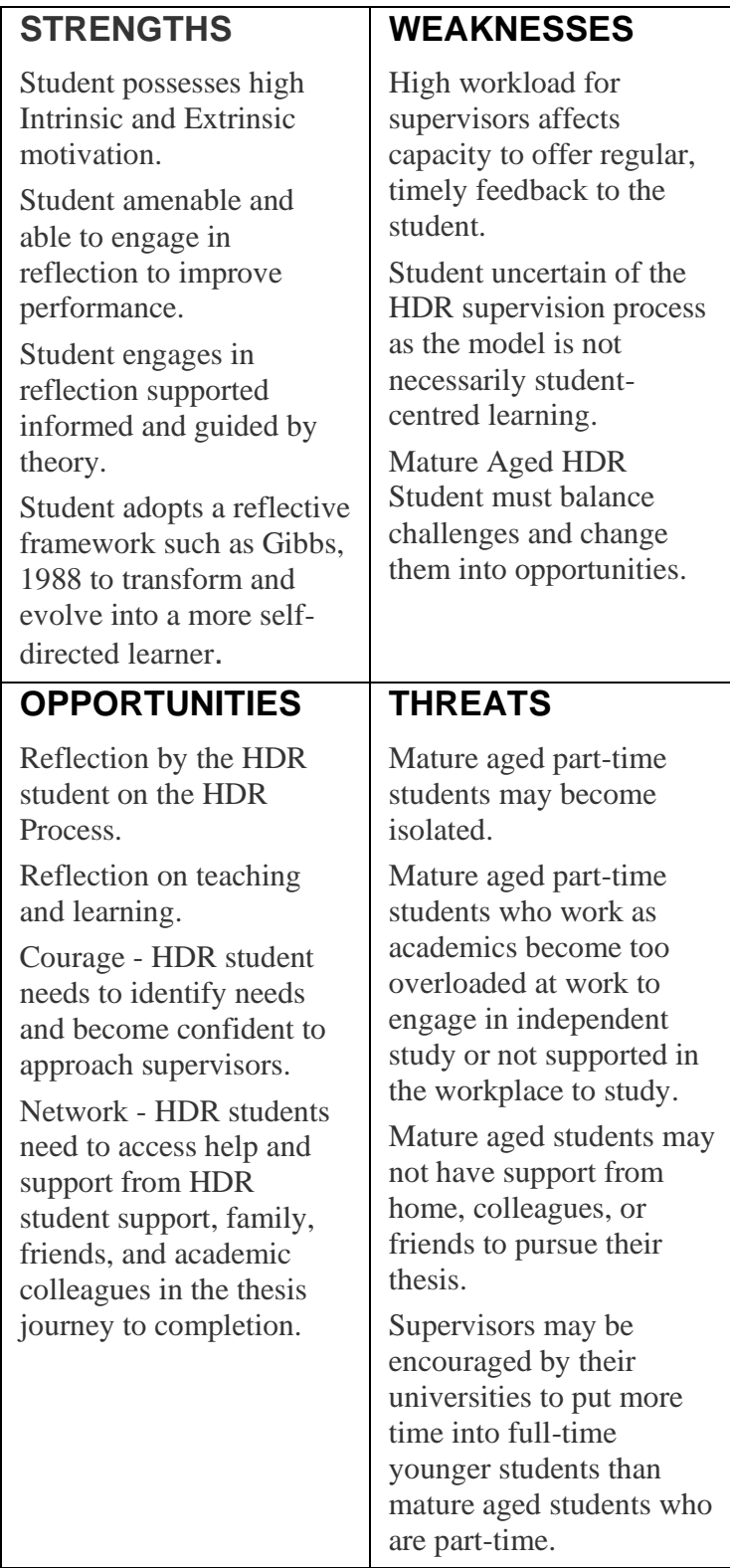

While working on my thesis I used the Gibbs' Six Stage model namely: Description of experience; Feelings and thoughts about experiences; Evaluation both positive and negative; Analysis of the experience such as what I learned; Action plan for what I would do differently to understand the impact arising from the process [2]. For the benefit of those unfamiliar with Gibbs model this is how it was useful to understand and explain the impact and achievements.

By describing the experience of navigating the thesis process, my thoughts and feelings were revealed. To the most part I felt happy and productive. However, at times I felt lost and felt unsure of my new HDR student role. My 'imposter syndrome self' reared its head and the experience of studying became a battle or hurdle marred by bouts of perfectionism [3], [1].

In addition, I was always conscious that I was using French and Raven's power types to understand how the relationships between myself and my two supervisors was progressing or not progressing [4].

The supervisors were mostly perceived as engaging in an expert power capacity due to their roles and experience. The primary supervisor had supported students to completion and had won teaching awards. However, one of the supervisors often engaged in a coercive power approach by writing feedback in a condescending or brusque tone to assert their authority [4], [9]. This caused me to feel a bit intimidated [9].

In hindsight, the tone I was hearing at the time seemed to be authoritarian and not collaborative. However, it appears that this was the way he provided feedback due to experiencing pressure due to his heavy teaching load. Therefore, his response was not personal. This had the effect of causing a stress reaction and stall my cognitive ability to move the key ideas in the thesis forward [4].

When I commenced my degree by research my expectations were focused on the traditional university style of learning, namely didactic teaching with limited or no opportunities to discuss issues, pose questions and acquire knowledge through cooperative learning [10]. As a distance student who studied fully online for several years, my experience of online learning had been mixed. In one postgraduate coursework unit I studied, all lectures were pre-recorded, there were no tutorials online, optional study questions were provided in a handbook and students sat a final exam. In the postgraduate units I studied in the latter part of my MA I had a much more meaningful experience with the university lecturer who became my original supervisor for my MA Hons.

Her classes engaged me in co-operative learning by her questioning techniques after splitting the class into study groups and case study analysis fostering social interdependence through cooperative work practices [10]. This was achieved by the provision of opportunities to engage with other students in online forums, wikis, and weekly tutorials [10]. In addition, the lecturer was approachable, guided learning and would engage one on one with students who booked appointments.

It became clear that I needed to construct my learning opportunities once I had navigated Mezirow's disorientating dilemma (my thesis). It was necessary to work through this dilemma to transform my thinking, writing and skills related to articulating 
a sequenced argument supported by a diverse body of evidence [11].

\section{Reasons Why the Thesis Model is Flawed}

Analysis of the traditional thesis by research model is essential to demonstrate challenges impacting students who are expected to take responsibility for their own learning. By traditional thesis model I refer to the progression through the higher degree by developing and submitting a dissertation for external examination [12].

The focus of this section relates to the personal reflection by the author of the impact of the dependency learning model of apprentice vs expert with supervisors and support that students need in an Australian context, but do not necessarily receive [13]. It is acknowledged that in the global context it may differ, and scaffolded support may be a standard professional learning expectation of the supervisors' responsibilities towards the students [13]. Professional doctorates usually have a sequenced learning pathway that requires successful coursework completion prior to commencement of the thesis.

The default model of supervision at universities is the apprentice (the student) vs expert (the HDR supervisor) which contravenes current educational learning and teaching practices, namely studentcentred learning [13]. Experienced HDR supervisors may argue that students should develop a sense of autonomy and ownership, described by Ryan and Deci of the projects when navigating the thesis process [5] However, students are restricted by rules and regulations. Often these rules of engagement are inconsistently applied, for a variety of reasons, such as actual time spent liaising with supervisors, and engagement in research which influences successful advancement through the thesis process [14].

There are guidelines at universities for the overall 'macro' Higher Degree Research student administrative process such as: selection of topic, setting expectation, achieving confirmation, doing the research, finalising the thesis plus what to do if things go wrong [15]. What is lacking is an operational 'micro' model of learning, whereby the student can engage in authentic learning with support of a mentor, at workshops using professional conversations to articulate support for their learning. Clear guidelines using examples such as progressive activities that focus on building relationships with key people in the HDR journey and getting to know your supervisors would be useful to help operationalise student and supervisor expectations [15].

If the traditional model of supervision remains the usual pathway to thesis completion, support and training needs to be integrated with student-supervisor relationship building exercises that would inform clear communication practice [13]. Clarity and sequencing of these activities such as analysis of case studies or situations, supported by an established micro model of learning would assist less confident students to commence conversations with supervisors [15].

Clear direction and guidance would encourage autonomous learning and skills acquired would transfer to working in an academic or similar context, post thesis completion [5] Skills such as self-directed learning, the ability to construct their own learning as well as positive engagement in research, are essential to carry a thesis to completion and transference to 'real world' activities [20]

\subsection{Student Centred Education Practice}

Even the most experienced, academically capable student would be confronted with the retrospective step of moving from a constructivist, student centred approach in undergraduate and postgraduate coursework degree programs back to a traditional model of teaching [15]. The traditional model of supervision where the teacher is the expert and student are the apprentice has merits such as encouraging independent learning [15], [16] One might argue that the student may have autonomy to select their own topic and is responsible for researching and producing a thesis to completion [5],[16] However, the actual support from supervisors for students needs to be scaffolded along the journey with awareness of the student's psychological needs [14]. Then specific milestones are negotiated as checkpoints used to assess the student's current and future levels of performance.

After consultation with the student, interventions and adjustments may be suggested to inform activities that would move the student to capability e.g., completion of the thesis [17]. Feedback strategies are a grey area as there are such a wide variety of mechanisms to provide it to students. Knowing which ones will be useful is not always apparent in this relationship [14] In addition, not all supervision relationships provide opportunities to engage in 360degree feedback so that the student can articulate whether specific feedback was helpful or needed to be explained in more detail [14]

\subsection{Knowledge and Knowing}

Knowledge and knowing how the macro and micro systems work is not always obvious to the diverse community of students undertaking higher degree research programs [19]. Knowles suggests that adults need to be involved in planning and providing feedback on learning. He offers a framework to make sense of the thesis journey where the self-concept of a student moves from being dependent on the supervisor to a self-directed learner [19]. Adult 
learners have a wealth of experience to refer to which should be a resource for learning. However, adult learners, particularly mature aged students may have barriers that impede their knowledge such as being tired from working long hours and children or elderly parent carer responsibilities.

Students need to know how to seek guidance and communicate their needs, sharing impediments or barriers, so that the supervisor can adjust expectations and segment tasks scaffolding learning [19]. By posing questions of clarification in a positive way to their supervisors in the micro system they should be able to elicit a useful response, but timing is also an issue ([14, [19]. Also, students do not always know what they do not know as there are limited opportunities for them to converse positively about these concerns with peers and supervisors [20]

In some professional doctorates, completion of coursework prior to working on the thesis is required. The expectation is that students would know how to transition more smoothly to the next phase, namely production of the thesis. However, some of the key steps such as: developing research questions, methodology and analysis need to have been studied during workshops or similar activities [12]. As part of the coursework students could learn how to reflect effectively on feelings, achievements, writing strategies, synthesis, and construction of parts of the thesis. This could be enhanced by using Gibbs' Model of reflection or alternative models such as those attributed to Johns or Kolb [2]. Knowing 'how to get a thesis' can be part of the battle. If the students lack knowledge about how the system works and the micro learning activities available to them, it can become a barrier to learning. Stress, fear of the unknown and feelings of helplessness would retain the student in the dependency phase rather than enable progression to become a self-directed learner [19].

\subsection{Navigating the Power Dynamics of Student-Supervisor}

The power dynamics that develop in a studentsupervisor relationship are varied and are discussed in the reflective narrative in part 5. Reflective Framework, earlier in this paper. Aguinis et al 1996, p. 270 describes power as 'a synonym for influence'. The French and Raven Model of Power, 1959 is useful for explaining the dyadic relationship between student and supervisor. The supervisor is the 'agent of power' who has the potential to alter 'the target' or student's behaviour, state of mind and value [4].

Thesis blogs such as the Thesis Whisperer in Australia provide evidence of the impact that a supervisor can have on a student due to their positional power. Stories of success and distress from the student and supervisor perspective highlight a concern for a supervision model that could, if left unchecked, be misused to 'get rid' of students who do not serve their supervisor or destroy the career of the supervisor [4], [21].

In my own case at the beginning of my studentsupervisor relationship the supervisor was the expert. I felt in awe and overwhelmed by the international standing of my supervisor and nervous about asking questions despite her being approachable. When I changed supervisors, due to her retirement from academia, I had another set of relationships to build, discussed in more detail in 4. Impressions of the Thesis Journey. These relationships moved through all the types of power articulated by French and Raven, 1959, depending on the stage of my thesis. Fortunately, I had a happy ending whereby the final phase, aligned with successful awarding of the thesis resulting in a collegial, referent power relationship by the time I finished [4].

A key issue that emerged, common in my group of peers was that supervisors usually had the last word. In some cases, where a student was completely 'off track' the supervisor carefully argued a case suggesting that changes at this point in the thesis were not viable. However, there is a delicate balance in the relationship that can at times border on coercion (Aguinis et al). Gibbs 1988 reflective cycle provides a framework for students to reflect on an incident of power such as coercion, where a supervisor response causes a disorientating dilemma, described by Mezirow e.g., the student thinks they have the theoretical model in their thesis integrated to support the overall research question [4], [5. The student expected the supervisor to support their idea but were surprised and unsure when the supervisor appeared to demolish their argument [4].

When this happens, it is important to remain calm, be confident about your argument but reflect on advice. In my own case I proposed a power model, unfamiliar to the second supervisor. Therefore, I had to articulate in a simple argument showing how I had applied a contemporary twentieth century model in an antique context to explain the types of power an imperial woman in the Sixth century accessed to successfully exert her influence or renegotiate relationships to pursue issues. He was satisfied by my explanation and argument which provided numerous examples of how it would enhance the overall thesis. However, if I had not felt confident about the integrity of my research it may have impacted negatively on my whole thesis.

\section{Issues Impacting upon the Thesis Process}

The process of completing your thesis cannot be covered in one paper. Some of the elements of the process and the impact of variables are covered in this article which serves as a first impressions overview. In subsequent papers the elements of the process and 
impact of variables will be included and explained in more detail with additional examples.

\subsection{Academic Supervision}

The process of completing the thesis is divided into several different parts that need to be navigated and managed to successfully complete the research degree. A significant part is that of supervisor-student relationship which students need to work on from commencement to completion. The supervision model for HDR students is flawed. The dynamics of teaching are supervisor and apprentice, something I have not experienced since I first started working decades ago.

My original supervisor retired at a critical point in the thesis process. She was incredibly supportive and worked with me to transition to a new supervision team. However, I found it difficult as I had to build a new relationship with both supervisors. This was time I had to make but due to working full-time became a challenge. While my supervisors were pleasant, hardworking, helpful, and effective, I found that the expert vs apprentice model stifled my ability to raise key issues, move my thesis forward or argue in a scholarly way about my work earlier in my candidature for fear of offending my supervisors or breaking protocol.

In fact, it was only when I was completing the final thesis and then working on the edits from the examiners that I found my voice and felt confident reasoning a position. This model is at odds with the way we are expected to teach our undergraduate and postgraduate coursework students e.g., student centred learning as opposed to didactic teaching. The learning point here is that when working in traditional learning structures it is important for students to take responsibility for their own learning early in the candidature.

Positive communication is the key. Keep communications civil. Be polite, listen or review any written feedback. It is okay to disagree but ask questions first to maintain positive communication. Be clear about what you need. Ask questions of clarification sooner rather than 'stewing' on a piece of feedback that you do not fully understand. Adopting strategies that improve your writing is also important, so you have something concrete to present to supervisors. Write regularly. I only 'got this' toward the end game part of the thesis.

\subsection{Employment Issues}

Considering the impact that employment has on the ability to develop and complete a thesis is an important consideration. As described earlier in the paper I commenced my thesis shortly after securing an academic lecturing position at my university. Initially, despite a high teaching load, I found that I could balance my teaching responsibilities with time spent on my thesis. Once I obtained tenure, I was offered a promotion to another organisational area working as a more senior lecturer in academic development. This role had less teaching responsibilities so I thought that I would have more energy for study in the evenings. However, the role involved considerable domestic travel across Australia for weeks on end. This became a challenge to completing regular, substantial work on the thesis. Work demands can be unpredictable so keep the key goal in mind - completion of the thesis and persevere even when the going gets tough or people try to put you off your game.

\subsection{Family and Health Issues}

On reflection I realise that I am fortunate to have a husband who supported my study from beginning to end. In addition, there were several friends and academic colleagues at my university and at other institutions who helped spur me on or discuss key issues with production of the thesis. One needs a small but supportive network to help you keep the focus. Family and Health issues dogged the thesis. Early in my candidature I had a few health emergencies from which I fully recovered. I felt like quitting the degree but sought advice from academic supervisors and the university suggesting I suspend the degree until I recovered. While reluctant to do so I suspended candidature. It was the best thing I did to keep going with the degree. I ended up having to suspend a few more times due to family issues.

During the latter part of my candidature three family members died in three years, my father had a medical episode and then the Covid 19 impacted on my ability to support relatives. The learning point here is that do not be afraid to request a suspension of candidature for solid reasons such as family issues or health. Unless you experience a crisis during your candidature, it is difficult to appreciate the impact it may have on your work, such as no energy or time to study. However, most students will find that somewhere along the line there will be issues. Persevere, do not give up. Just keep the goal in mind.

\section{Motivation}

One of the key aspects of successful thesis completion is motivation. Fortunately, I have high intrinsic as well as extrinsic motivation. Intrinsic motivation manifested through my enjoyment of study, academic challenges to achieve a higher standard of education and I was interested in the topic [5].

Whereas extrinsic motivation was maintained by needing to complete the degree for my support network not just for myself. Navigating the medical barriers left me with a stronger will to succeed as did 
the issues around work and employment. Colleagues at my university encouraged me to connect with domestic as well as international academics through conferences and other face to face workshops. My goal was achieving the academic award of $\mathrm{PhD}$.

Motivation can be achieved by perseverance and engagement in activities that you enjoy (intrinsic) or positive feedback that help you scaffold your journey to achieve the award [5]. The learning point is that one should seek advice, read widely and do not be afraid to try to publish. Feedback from successful and unsuccessful submissions to journals will provide you with valuable professional development to improve your success.

\section{Transformative Learning}

Transforming your learning occurs whether you notice it or not. As an HDR candidate I felt I did not notice the changes in the strategies I adopted to engage in research. However, colleagues, family and academic supervisors ensured that I took note of small, regular changes.

To improve my study time management during my candidature, I approached the academic skills unit for assistance. Numerous strategies to improve focus and time management were suggested. However, the one that was the most useful was using the Pomodoro technique [8]. The idea is that you allocate a 25minute timeslot to complete a task. The principle behind it encourages one to use time more effectively by either using a timer on your mobile telephone, a 'tomato or pomodoro' app on your desktop or an egg timer.

I found an online pomodoro app and adopted this technique to focus my time on a specific task such as reading through supervisor feedback on a piece of writing or a chapter and highlighting key edits. Sometimes that might take seven times 25-minute pomodoro sessions. It took some getting used to, but I found it helpful and continue to use this in other aspects of my life and for focus at my university when completing my academic work. It is useful for marking, developing course materials, and writing academic papers as regular breaks mean one has more energy and focus.

There were numerous dimensions to the transformative learning that I experienced during my academic candidature the first being psychological wellness. Practicing wellness techniques, mindfulness and engaging in fitness pursuits were strategies I adopted to manage the stress and impact that the thesis journey had on my life. Focusing my mind at specific times of the day in the morning, lunchtime and in the evening helped me manage my time at work and study more effectively. This was not an easy feat. I used a variety of methods such as using the My Life (formerly the Stop, Breathe Think) App to engage in short, guided meditation [6].
Sometimes I just sat in a comfortable position at home in the evening and focused on the flame of a candle, clearing my mind of clutter. In addition, I engaged in regular FIIT 30 targeted gym training sessions and worked with a personal trainer twice a week to keep physically and mentally fit. Physical fitness has always been a feature in my life, and it improved my mood, attitude towards study and resilience [6].

\section{Conclusion}

The truth is that I did not fully understand the overt and covert practical, sociological, and psychological processes involved in researching, preparing, constructing, and editing a thesis to completion. Therefore, to help other students and HDR supervisors navigate a positive learning and teaching experience which builds resilience, I was compelled to provide an overview reflection, supported by scholarship about my experiences, in this introductory paper. The key things that I learned was how to manage obstacles. I used my high intrinsic motivation to spur me along and take note of transformations in my learning which manifested when I achieved milestones, obtained unsolicited feedback from peers, and received invitations from colleagues to participate in research. In subsequent papers I intend to provide more detail about the processes at the beginning, middle and end of the thesis journey which will inform a framework to assist both HDR students and supervisors.

\section{References}

[1] C. Wilkinson, "Imposter syndrome and the accidental academic: an autoethnographic account", International Journal for Academic Development, Vol. 25, (4), Routledge Taylor and Francis, Online, 2020, pp. 363-374.

[2] A. Wain, "Learning Through Reflection", British Journal of Midwifery, Vol. 25, (10), October 2017, pp. 662666.

[3] A. Sverdilk, C. Nathan. and L. McAlpine, "PhD Imposter Syndrome: Exploring Antecedents, Consequences and Implications for Doctoral Well-Being", International Journal of Doctoral Studies, Vol. 15, 2020, pp. 137-758.

[4] H. Aguinis, Nesler, M.S, Quigley, B.M., S. Lee, S and J. Tedeschi, "Power Bases of Faculty Supervisors and Educational Outcomes for Graduate Students", The Journal of Higher Education, Vol. 67, (3), 1996, pp. 267-297.

[5] R.M. Ryan and E.L. Deci, "Intrinsic and extrinsic motivation from a self-determination theory perspective: Definitions, theory, practices and future directions", Contemporary Educational Psychology, Vol. 61, Elsevier, Online, 8 April 2020, pp. 1-11. 
[6] S.M. Neace, A.M. Hicks, M.S. De Caro and P.G. Salmon, "Trait mindfulness and intrinsic exercise motivation uniquely contribute to exercise self-efficacy", Journal of American College Health, Taylor and Francis Online, 28 April 2020, DOI: $10.1080 / 07448481.2020 .1748041$.

[7] J.C. Coulson, "Exercising at work and self-reported work performance" International Journal of Workplace Health Management, Vol. 1, (3), Emerald Group Publishing, 2008, pp. 176-197.

[8] Cirillo, F, The Pomodoro Technique: The Life-Changing Time-Management System, Ebury Publishing, Google Books online, 2018.

[9] M. Kovach, "Leader Influence: A Research Review of French and Raven's (1959 Power Dynamics", The Journal of Values-Based Leadership, Vo. 13, Issue 2, Article 15. http://dx.doi.org/10.22543/0733.132.1312.

[10] L. Baloche and C.M. Brody, "Co-operative learning: exploring challenges, crafting innovations, Journal of Education for Teaching, Vol. 43, (3), Routledge Taylor and Francis, 2017, pp. 274-283.

[11] S. Eschenbacher and T. Fleming, "Transformative dimensions of lifelong learning: Mezirow, Rorty and COVID-19", International Review of Education, Springer, online, 2020

https://doi.org/10.1007/s11159-020-09859-6.

[12] G. Stewart-Wells and M. Keenan, "Assessing Doctoral Students: A Background on Comprehensive and Authentic Assessments", The Journal of Continuing Higher Education, Vol. 68, (2).

[13] S. Harrison and C. Grant), "Exploring of new models of research pedagogy: time to let go of master-apprentice style supervision?" Teaching in Higher Education, Vol. 20, (5), pp. 556-566.

[14] S. Jabeen, Hashmi, A. and M. Halid, Jabeen, S. Hashmi, A. and Halid, M. "Expectation of Research Students about Online Supervision of Thesis Supervisors: A Case Study of Virtual University of Pakistan”, Global Sciences Review (GSSR), Vol. 5, (2), 2020, pp: 126-136.

[15] M.B. Fisher, "HDR Supervision 2: Reflection on Support of a Mature Aged Student with Diverse Needs", International Journal of Technology and Inclusive Education (IJTIE), Special Issues, Vol. 3, Issue 1, 2016.

[16] Van Rooij, "Factors that influence PHD candidates' success: the importance of PHD project characteristics", Studies in Continuing Education, 2019, pp. 1-19.

[17] P. Smagorinsky, "Deconflating the ZPD and instructional scaffolding: Retranslating and reconceiving the zone of proximal development as the zone of next development", Learning, Culture and Social Interaction, Vol. 16, 2018, pp. 70-75.
[18] B. Holmes, L.T.M. Brown, M. Parker, J. Mann, E. L. Woods, J.A. Gibson, T. L. Best, V. Diggs, C. Wilson and D. Hall, "Decoding the Persistence and Engagement Patterns of Doctoral Students Who Finish", Education Doctorate Faculty Works, Vol. 11.

[19] V. Rowtho, S. Gopee and A. Hingun, "Doctoral boot camps: from military concept to andragogy", Education and Training, Vol. 62, (4),2020, pp. 379-392.

[20] T. Anderson, "The Socialization of L2 Doctoral Students through Written Feedback", Journal of Language, Identity and Education, 2020.

[21] Ingar Mewburn, 'The Thesis Whisperer' Blog, Located at: https://thesiswhisperer.com (Accessed Date: 5 February, 2021). 